\title{
Impact of poor host-parasitoid synchronisation on the parasitism of Cameraria ohridella (Lepidoptera: Gracillariidae)
}

\author{
Giselher GRABENWEGER ${ }^{1 *}$, Hildegard HOPP ${ }^{1}$, Barbara JÄCKEL ${ }^{2}$, Hartmut BALDER ${ }^{1}$, TANJa KOCH ${ }^{1}$ \\ and SILKE SCHMOLLING ${ }^{1}$
}

\author{
${ }^{1}$ University of Applied Sciences Berlin, Luxemburger Strasse 10, D-13353 Berlin, Germany \\ ${ }^{2}$ Official Bureau of Plant Protection Berlin, Mohriner Allee 137, D-12347 Berlin, Germany
}

\begin{abstract}
Key words. Lepidoptera, Gracillariidae, Cameraria ohridella, leafminer, horse chestnut, Aesculus hippocastanum, parasitoid,
\end{abstract} Hymenoptera, Eulophidae, parasitism, synchronisation, biological control

\begin{abstract}
Poor synchronisation is considered to be one important reason for the ineffective control of the invasive horse chestnut leafminer by native parasitic Hymenoptera. Parasitoids hibernating in dry horse chestnut leaves break diapause early in spring and presumably leave the vicinity, since no hosts are available when they emerge. As a consequence, the percentage parasitism of the first generation of the leafminer in early summer is low. The experiments presented below were designed to test this hypothesis. Horse chestnut saplings were brought on in a greenhouse and infested artificially with C. ohridella prior to parasitoid emergence in the field. These saplings were then exposed to parasitoid attack under natural conditions to eliminate the synchronisation problem. In addition, the parasitoid complexes of other leafmining hosts, which appear early in the season, were analysed. The results confirm that the most important parasitoids of the horse chestnut leafminer are active early in the season, long before the larvae of the first generation of the host are present. Nevertheless, poor synchronisation with the invasive host did not significantly influence the abundance of the most important parasitoid in the complex, Minotetrastichus frontalis, and consequently had no impact on the parasitism of $C$. ohridella. Nevertheless, a detailed analysis of the parasitoid community shows that certain species are affected by poor synchronisation, while others are probably limited by ecological parameters, such as a specialisation to foraging in particular strata of vegetation. Several leafmining flies were found early in spring infesting other host plants commonly planted in urban green areas, including species with a parasitoid complex similar to that of $C$. ohridella. The role of these alternative hosts in the food web associated with the horse chestnut leafminer should be subject to further study.
\end{abstract}

\section{INTRODUCTION}

The horsechestnut leafminer, Cameraria ohridella Deschka \& Dimić 1986, colonizes mainly the leaves of the common horse chestnut, Aesculus hippocastanum L. The continuous infestation of these trees by this small and inconspicuous moth arouses great public concern, because horse chestnuts are commonly planted in European cities and the damage caused by the feeding larvae is unsightly. After colonizing a new region, the leafminer reaches epidemic population densities within a few years. Conspicuously, these mass outbreaks of the pest have so far not significantly decreased at any place in Europe. One important reason for the continuous heavy infestation of horse chestnut trees by the leafminer is probably the ineffectiveness of natural control mechanisms (Heitland et al., 2003).

Usually, parasitic Hymenoptera contribute significantly to the control of leafminer populations, which sometimes suffer a heavy parasitism of $50 \%$ or more (e.g. Miller, 1973; Askew \& Shaw, 1979; Cornell \& Hawkins, 1993; Mey, 1993). In contrast, parasitism of Cameraria ohridella is very low, parasitism levels of more than $5 \%$ are rarely recorded in Central Europe (Freise $\&$ Heitland, 2004). Grabenweger (2004) proposed that poor synchronisation between the emergence of the parasitoids after diapause and the development of the host's first generation is one important reason for the ineffectiveness of the parasitoids in spring. At the time when the bulk of the parasitoids emerge from dry leaves after diapause, neither mines, nor even eggs of the host are present on horse chestnut leaves. Stages of $C$. ohridella suitable for parasitism appear about a month later. Similar observations were published by Hellrigl (2003). Consequently, the majority of the parasitoids emerge in horse chestnut stands several weeks before $C$. ohridella hosts become available.

Parasitism of first generation C. ohridella must therefore come from one of two possible sources: Firstly, old and/or lateemerging specimens of the overwintering generation of parasitoids initiate parasitism of $C$. ohridella in spring, as suggested by Girardoz et al. (2006). Secondly, the parasitoids are polyphagous and use alternative hosts in the surrounding vegetation. Their offspring switch to $C$. ohridella as soon as suitable larval stages become available. This is considered to be more likely by Grabenweger (2004) because the parasitoid complex associated with $C$. ohridella in Europe is dominated by idiobionts of the chalcidoid family Eulophidae. From 40 to far more than 100 different lepidopteran, coleopteran, dipteran and hymenopteran hosts may be attacked by the relevant species according to the records listed in Noyes (2002). Presumably, these parasitoids switch easily to other hosts as soon as they become available.

In the present study, the theory of poor synchronisation in this host-parasitoid complex was tested by providing the parasitoids with artificially infested horse chestnut when they emerged from hibernation in spring. In this way, the development of the host and parasitoid was synchronized and the build up of the parasitoid population on the experimental plants proceeded unimpaired. In addition, potential hosts, other than C. ohridella, in

\footnotetext{
* Current and corresponding address: Austrian Agency for Health and Food Safety, Institute for Plant Health, Spargelfeldstrasse 191, 1226 Vienna, Austria; e-mail: giselher@grabenweger.at
} 
TABLE 1. Details of the method, percentage parasitism (mean \pm standard deviation) and number of parasitoid species in the samples $\left(\mathrm{G} 1=1^{\text {st }}\right.$ generation of the leafminer).

\begin{tabular}{|c|c|c|c|c|c|c|c|}
\hline host insect & host plant (n) & location & start date & $\begin{array}{c}\text { sampling } \\
\text { date }\end{array}$ & exposure period (days) & $\begin{array}{l}\text { para- } \\
\text { sitism }\end{array}$ & $\begin{array}{c}\text { no. of } \\
\text { species }\end{array}$ \\
\hline Cameraria ohridella & A. hipp. dry leaves & $\begin{array}{c}\text { horse } \\
\text { chestnut }\end{array}$ & - & 14.04 .2005 & previous autumn & - & 10 \\
\hline C. ohridella & A. hipp. Saplings (25) & $\begin{array}{l}\text { horse } \\
\text { chestnut }\end{array}$ & 14.04 .2005 & 27.05 .2005 & prior to G1 (44) & $12.2 \pm 7.8$ & 9 \\
\hline C. ohridella & A. hipp. Saplings(26) & control & 15.04 .2005 & 25.05 .2005 & prior to G1 (40) & $4.5 \pm 3.8$ & 4 \\
\hline C. ohridella & A. hipp. Saplings(20) & $\begin{array}{c}\text { horse } \\
\text { chestnut }\end{array}$ & 08.06 .2005 & 07.07 .2005 & concurrent with G1 (29) & $15.6 \pm 9.7$ & 8 \\
\hline C. ohridella & A. hipp. Saplings(15) & control & 09.06 .2005 & 07.07 .2005 & concurrent with G1 (28) & $11.8 \pm 7.2$ & 4 \\
\hline C. ohridella & A. hippocastanum (8) & $\begin{array}{l}\text { horse } \\
\text { chestnut }\end{array}$ & - & 04.07 .2005 & concurrent with G1 & $5.6 \pm 4.9$ & 3 \\
\hline Phytomyza ilicis & Ilex aquifolium & $\begin{array}{l}\text { horse } \\
\text { chestnut }\end{array}$ & - & 27.05 .2005 & prior to $\mathrm{G} 1$ & - & 4 \\
\hline Monarthropalpus buxi & Buxus sempervirens & $\begin{array}{l}\text { horse } \\
\text { chestnut }\end{array}$ & - & 27.05 .2005 & prior to G1 & - & 2 \\
\hline Agromyzidae spp. & Lonicera xylosteum & $\begin{array}{l}\text { horse } \\
\text { chestnut }\end{array}$ & - & 27.05 .2005 & prior to $\mathrm{G} 1$ & - & 9 \\
\hline Agromyzidae sp. & Medicago sativa & control & - & 01.06 .2005 & prior to $\mathrm{G} 1$ & - & 3 \\
\hline
\end{tabular}

the vicinity of the horse chestnuts in spring were identified. If poor synchronisation is important, these hosts may provide the parasitoid complex in a local horse chestnut stand with an alternative resource before the first generation of $C$. ohridella reaches a developmental stage suitable for parasitoid attack.

\section{MATERIAL AND METHODS}

2-4 year old horse chestnut saplings of approximately $1 \mathrm{~m}$ shoot length were brought on in a green house $\left(22^{\circ} \mathrm{C}, 70 \% \mathrm{rH}\right.$, $16 \mathrm{~h}$ daylight). They were infested with $C$. ohridella after the leaves had fully developed. Moths used for infestation were reared from leaf litter collected in October and November 2004 and stored in the dark at $2^{\circ} \mathrm{C}$, without humidity control.

The infestation of the saplings was carefully timed. Previous studies have shown that the late feeding instars as well as the two subsequent spinning instars of the leafminer are the most susceptible to parasitoid attack (Grabenweger, 2003). Therefore, the first batch of 50 saplings was infested so that the juvenile leafminer population reached the optimum age for parasitism $\left(4^{\text {th }}-6^{\text {th }}\right.$ larval stage $)$ just at the time when parasitoids in the field emerged from hibernation. According to Grabenweger (2004) and Girardoz et al. (2006), parasitoid emergence coincides with the emergence of $C$. ohridella in spring. We therefore estimated the emergence date based on the $C$. ohridella pheromone monitoring data of the Official Bureau of Plant Protection in Berlin collected over the last 3 years and calculated the correct infestation date for the saplings by subtracting 24 days. This was the time necessary for oviposition and development of juvenile leafminers to the stage suitable for parasitism in the laboratory (Grabenweger et al., in prep.).

A second batch of 50 saplings was infested 4 weeks later so that this population developed in parallel with the first generation of C. ohridella in the field. The infested saplings were exposed to parasitoid attack at two different locations, a horse chestnut stand and a control site without horse chestnuts (Table 1).

Saplings were removed after exposure for 6 weeks (first exposure) and 4 weeks (second exposure), respectively, when the majority of the non-parasitized leafminers were emerging from the leaves. The mines on the 4 largest leaves of each sapling were carefully dissected to assess percentage parasitism. The percentage of parasitized mines in relation to the total number of mines dissected was used.

The remaining leaves were stored in emergence traps made from 251 tubs painted with black acrylic paint. A hole was cut in the lid and covered with a funnel. Transparent boxes, acting as trap containers, were mounted on top of these funnels. Parasitoids collected from the trap containers were used to determine the parasitoid complex. Another two emergence traps filled with dry leaves prior to parasitoid emergence in spring were used to determine the parasitoid complex hibernating in horse chestnut leaves.

In addition, the percentage parasitism and the parasitoid complex associated with mature trees in the horse chestnut stand were determined using the same methods. Last but not least, leafminers infesting other plants at the same sites during the first exposure period were also surveyed. The suitability of these leafminers as alternative hosts was estimated by comparing their parasitoid complexes (using data from emergence traps) with that of C. ohridella.

\section{RESULTS}

Our experimental setup resulted in 5 samples of leaves for dissection, which yielded quantitative results that were used to estimate percentage parasitism, and 10 samples from emergence traps, which yielded qualitative results used to elucidate parasitoid complexes (Table 1)

\section{Percentage parasitism}

The percentage parasitism of $C$. ohridella on artificially infested saplings placed in the horse chestnut stand, when the parasitoids emerged from hibernation, was similar to that of moths infesting saplings exposed concurrently with the natural occurrence of the first generation at the same location (Table 1; U-test: $\mathrm{z}=-1.037$, asymp. sig. $=0.300$ ). The percentage parasitism of the naturally developed first generation on the mature horse chestnut trees was significantly lower than that of the moths infesting the saplings exposed concurrently beneath these trees (U-test: $\mathrm{z}=-3.027$, asymp. sig. $=0.002)$. At the control site (without horse chestnuts and consequently without infested 
TABLE 1. Parasitoid complex associated with C. ohridella, which emerged from dry leaves, samples of leaves from saplings exposed prior or concurrent with the $1^{\text {st }}$ generation of the leafminer and mature trees at the horse chestnut stand and control site (numbers in brackets show percentage composition, G1 $=1^{\text {st }}$ generation of the leafminer).

\begin{tabular}{|c|c|c|c|c|c|c|c|c|c|c|c|c|}
\hline \multirow{3}{*}{$\begin{array}{l}\text { parasitoid species } \\
\text { Cirrospilus vittatus Walker }\end{array}$} & \multirow{2}{*}{\multicolumn{2}{|c|}{$\frac{\text { autumn foliage }}{\text { horse chestnut }}$}} & \multicolumn{4}{|c|}{ saplings prior to G1 } & \multicolumn{4}{|c|}{ saplings concurrent with G1 } & \multirow{2}{*}{\multicolumn{2}{|c|}{$\frac{\text { G1 on trees }}{\text { horse chestnut }}$}} \\
\hline & & & \multicolumn{2}{|c|}{ horse chestnut } & \multicolumn{2}{|c|}{ control } & \multicolumn{2}{|c|}{ horse chestnut } & \multicolumn{2}{|c|}{ control } & & \\
\hline & 1 & $(1,9)$ & & & & & & & & & & \\
\hline Elachertus inunctus Nees & & & & & & & 4 & $(1,4)$ & 1 & $(1,1)$ & & \\
\hline Chrysocharis nepherea (Walker) & 2 & $(3,7)$ & 5 & $(4,0)$ & 3 & $(4,7)$ & 23 & $(8,3)$ & 13 & $(14,4)$ & 1 & $(9,1)$ \\
\hline Chrysocharis pentheus (Walker) & & & 17 & $(13,5)$ & & & & & & & & \\
\hline Closterocerus trifasciatus Westwood & 3 & $(5,6)$ & 4 & $(3,2)$ & & & 2 & $(0,7)$ & & & & \\
\hline Neochrysocharis chlorogaster (Erdös) & & & 5 & $(4,0)$ & & & & & & & 2 & $(18,2)$ \\
\hline Pediobius saulius (Walker) & 1 & $(1,9)$ & & & & & & & & & & \\
\hline Pnigalio agraules (Walker) & 8 & $(14,8)$ & & & & & 25 & $(9,1)$ & & & & \\
\hline Pnigalio pectinicornis (L.) & & & 13 & $(10,3)$ & 5 & $(7,8)$ & 53 & $(19,2)$ & 64 & $(71,1)$ & & \\
\hline Sympiesis sericeicornis (Nees) & 2 & $(3,7)$ & 18 & $(14,3)$ & 29 & $(45,3)$ & & & & & & \\
\hline Baryscapus nigroviolaceus (Nees) & 1 & $(1,9)$ & & & & & & & & & & \\
\hline Minotetrastichus frontalis (Nees) & 31 & $(57,4)$ & 56 & $(44,4)$ & & & 148 & $(53,6)$ & & & 8 & $(72,7)$ \\
\hline Colastes braconius (Haliday) & 2 & 3,7 & 4 & $(3,2)$ & 27 & $(42,2)$ & 14 & $(5,1)$ & 12 & $(13,3)$ & & \\
\hline Itoplectis alternans (Gravenhorst) & & & 4 & $(3,2)$ & & & & & & & & \\
\hline Scambus annulatus (Kiss) & 3 & $(5,6)$ & & & & & 7 & $(2,5)$ & & & & \\
\hline no. of species & 10 & & 9 & & 4 & & 8 & & 4 & & 3 & \\
\hline total individuals & 54 & & 126 & & 64 & & 276 & & 90 & & 11 & \\
\hline
\end{tabular}

leaf litter), percentage parasitism increased almost by a factor of three between the two exposure periods (T-test: $\mathrm{t}=-4.200, \mathrm{df}=$ 15.957, sig. $=0.001)$.

\section{Parasitoid complex associated with $C$. ohridella infesting horse chestnut}

A total of 621 individuals of 15 different parasitoid species were reared from the emergence traps containing $C$. ohridellainfested leaves (Table 2). With the exception of the extraordinarily poor sample from the $1^{\text {st }}$ generation of the leafminer on the mature trees, species richness is about twice as high in samples collected at the horse chestnut stand than at the control site. However, only $50 \%$ of the complexes reared from the dry horse chestnut leaves and the saplings exposed at the same site were similar. Species richness did not increase between the two exposure dates, either at the horse chestnut stand or the control site, where percentage parasitism increased significantly during the same period (see above).

Distribution of the species among the samples depended on the location, the exposure date and the age of the host plant, which was well demonstrated by the distribution of three very abundant species (Table 2). Most of the parasitoids were Minotetrastichus frontalis. At the horse chestnut stand, this species dominated the parasitoid complex that hibernated in the dry leaves as well as those attacking the moth infesting the saplings on both exposure dates and the leafminer's $1^{\text {st }}$ generation on mature trees. However, not a single individual of this species was reared from the saplings placed at the control site, regardless of the time of exposure.

Sympiesis sericeicornis was very abundant in the samples from the first exposure experiment. At this time, this species even dominated the sample from the control site. In contrast, no $S$. sericeicornis were reared from any sample exposed during the leafminer's $1^{\text {st }}$ generation a month later, neither from saplings nor the leaves of mature horse chestnut.
The occurrence of Pnigalio pectinicornis was not associated with a particular exposure date. The abundance of this species even increased in the samples from the second batch of exposed saplings. However, $P$. pectinicornis was never found in mines from mature trees, neither in the dry autumn leaves nor those of the leafminer's first generation on mature horse chestnut. Surprisingly, this species was the second most abundant parasitoid of the moth infesting saplings exposed beneath trees at the time of the development of the first generation of $C$. ohridella in the field.

\section{Parasitoid complexes associated with other host plants}

Juvenile stages of several different endophytic host insects were recorded at the study sites, prior to the appearance of the first $C$. ohridella mines. At the horse chestnut stand, there were the following: Monarthropalpus buxi (Laboulbene) on box (Buxus sempervirens), Phytomyza ilicis (Curtis) on holly (Ilex aquifolium) and a complex of Aulagromyza spp. and Chromatomyia lonicerae (Robineau-Desvoidy) on honeysuckle (Lonicera xylosteum). An undetermined agromyzid leafminer on alfalfa (Medicago sativa) was found at the control site. Their parasitoid complexes were compared to that of $C$. ohridella on horse chestnut saplings exposed at the same time and to that hibernating in horse chestnut leaves (Table 3). The complex parasitizing the agromyzids on honeysuckle best matches that parasitizing C. ohridella. $40 \%$ of the parasitoid species that overwintered in C. ohridella mines and $60 \%$ of the species parasitizing the moth infesting contemporaneously exposed horse chestnut saplings were also found on honeysuckle. Only 3 species were reared from the agromyzid leafminer on alfalfa; however, the same species were also recorded from $C$. ohridella. In contrast, none of the $C$. ohridella parasitoids were recorded from M. buxi, and of the complex parasitizing P. ilicis only one species parasitized the horse chestnut leafminer. 
TABLE 1. Parasitoid complex associated with C. ohridella and 4 early appearing leafmining flies infesting other plants at the same locations.

\begin{tabular}{|c|c|c|c|c|c|c|}
\hline \multirow{2}{*}{ parasitoid species } & C. ohridella & C. ohridella & $\begin{array}{l}\text { Agromyzidae } \\
\text { spp. }\end{array}$ & $\begin{array}{c}\text { Agromyzidae } \\
\text { sp. }\end{array}$ & Phytomyza ilicis & $\begin{array}{c}\text { Monarthropalpus } \\
\text { buxi }\end{array}$ \\
\hline & autumn leaves & saplings & $\begin{array}{l}\text { Lonicera } \\
\text { xylosteum }\end{array}$ & $\begin{array}{l}\text { Medicago } \\
\text { sativum }\end{array}$ & Ilex aquifolium & $\begin{array}{c}\text { Buxus } \\
\text { sempervirens }\end{array}$ \\
\hline Cirrospilus vittatus & 1 & & & & & \\
\hline Chrysocharis nepherea & 2 & 5 & & & & \\
\hline Chrysocharis pentheus & & 17 & 25 & 12 & & \\
\hline Closterocerus trifasciatus & 3 & 4 & 2 & & 1 & \\
\hline $\begin{array}{l}\text { Neochrysocharis } \\
\text { chlorogaster }\end{array}$ & & 5 & 1 & & & \\
\hline Pediobius saulius & 1 & & & & & \\
\hline Pnigalio agraules & 8 & & & & & \\
\hline Pnigalio pectinicornis & & 13 & 1 & 1 & & \\
\hline Sympiesis sericeicornis & 2 & 18 & & & & \\
\hline Baryscapus nigroviolaceus & 1 & & & & & \\
\hline Minotetrastichus frontalis & 31 & 56 & 9 & & & \\
\hline Colastes braconius & 2 & 4 & 3 & 6 & & \\
\hline Scambus annulatus & 3 & & & & & \\
\hline Itoplectis alternans & & 4 & & & & \\
\hline Diglyphus minoeus (Wlk.) & & & 3 & & & \\
\hline Cyrtogaster vulgaris Wlk. & & & & & 6 & \\
\hline indet. Encyrtidae & & & 1 & & 1 & \\
\hline indet. Braconidae & & & & & 10 & 1 \\
\hline indet. Tetrastichinae & & & & & & 5 \\
\hline indet. Ichneumonidae & & & 1 & & & \\
\hline
\end{tabular}

\section{DISCUSSION}

The percentage parasitism of the moth infesting saplings exposed early at the horse chestnut stand was higher than that previously recorded in the city of Berlin (Jäckel et al., 2006) but does not exceed rates previously published for other European locations (e.g. Grabenweger et al., 2005). This shows that parasitoids emerging from hibernation start to search for leafminers immediately. In addition, other potential parasitoids of $C$. ohridella, emerging from other hosts in urban environments, are active in early spring, several weeks before the first $C$. ohridella mines appear on horse chestnut. Percentage parasitism of the moth infesting saplings exposed contemporaneously with the first leafminer generation on mature horse chestnut at the same location, however, was similar. Experimentally synchronizing the parasitoid and host did not increase parasitism rates. Obviously, poor synchronisation between native parasitoids and the invasive leafminer does not significantly affect the level of parasitism of C. ohridella in spring.

The low parasitism of the moth infesting early exposed saplings at the control site may be attributed to the absence of parasitoids, which emerge from dry horse chestnut leaves. The parasitoids attacking $C$. ohridella on these saplings must have hibernated on other hosts and switched to parasitizing the artificially provided horse chestnut leafminer. The samples from the second exposure experiment, however, show that the percentage parasitism at the control site was considerably higher, reaching a level comparable to that at the horse chestnut stand. This increase was not attributable to a higher species richness but to parasitoids, which were already present early in the year, par- ticularly $P$. pectinicornis, which was very abundant. Nevertheless, it is clear that the relatively high percentage parasitism at the control site does not come from the parasitoid community hibernating in horse chestnut leaves. From a quantitative point of view, the latter source is therefore fairly unimportant for the control of the first generation of the leafminer in spring and may be replaced by parasitoid recruitment from other hosts.

The most surprising result of the second exposure experiment was the significant difference in the percentage parasitism recorded for the naturally developed first generation of $C$. ohridella on mature horse chestnut and of artificially infested saplings located beneath these trees. These populations were exposed to parasitoid attack at the same time, which rules out any effect of bad synchronisation. In addition, the close proximity of the saplings to the trees excludes any influence of different parasitoid sources. The parasitism of the moth on mature horse chestnut was therefore negatively affected by factors other than those mentioned above.

With regard to these quantitative results, it is tempting to conclude that neither poor synchronisation nor the availability of parasitoids hibernating in horse chestnut leaves is important for the control of the first leafminer generation in spring. However, these conclusions do not apply to all the parasitoids in the complex. M. frontalis clearly dominated the parasitoid complex in the horse chestnut stand. It is by far the most abundant parasitoid of $C$. ohridella recorded in many previous investigations (among others Grabenweger \& Lethmayer, 1999; Hellrigl, 2001; Horváth \& Benedek, 2001; Freise \& Heitland, 2004). In contrast, not a single $M$. frontalis was found at the control site. Undoubtedly, the specimens reared from the samples from the 
horse chestnut stand did not originate from an extraneous host resource. They were the offspring of old or late-emerged specimens of the parasitoid community hibernating in horse chestnut leaves, as suggested by Girardoz et al. (2006). The early emergence of the majority of this species, as recorded in Grabenweger (2004) and in Girardoz et al. (2006), apparently did not substantially affect the abundance of this species. It is important to note that $M$. frontalis often develops gregariously on $C$. ohridella, which reduces the reliability of data from emergence traps (Hellrigl, 2001). Nevertheless, our results indicate that $M$. frontalis parasitism of the horse chestnut leafminer is mainly determined by factors other than poor synchronisation.

The opposite is true for $S$. sericeicornis. The abundance of this species in our samples indicates that poor synchronisation may seriously affect particular host-parasitoid relations. While $S$. sericeicornis was very abundant or even dominant in the samples from the early exposed saplings, not a single individual was found in the samples from those put out later or from mature trees. Unlike $M$. frontalis, most of the individuals from the saplings originated from other hosts, as demonstrated by the high abundance of this species at the control site. The few individuals hibernating in horse chestnut leaves are presumably forced to switch to another host in early spring, possibly one or more of the 138 hosts listed in Noyes (2002). However, our rearing results suggest that few of the subsequent generations of $S$. sericeicornis switch back later in the season, when juvenile stages of $C$. ohridella are available. At this time, other hosts common in urban environments may be the prime target of $S$. sericeicornis. For example, this species is known as a major parasitoid of Phyllonorycter platani on plane trees or P. robiniella on black locust, but is rarely abundant in C. ohridella complexes (Hellrigl, 2001; Horváth \& Benedek, 2001).

The high abundance of $P$. pectinicornis in samples from saplings exposed in the second period shows that this species is not affected by poor synchronisation with $C$. ohridella. As in $S$. sericeicornis, this parasitoid emerged from alternative hosts and did not consist of old or late-emerging individuals, as demonstrated by its high abundance at the control site and complete absence in dry autumn leaves. However, although highly abundant in samples from horse chestnut saplings, not a single individual was found in samples from mature trees. One reason may be a preference of this species for a certain stratocoenosis, as recorded for other parasitoid species (Zwölfer, 1962; Mey, 1991). An analysis of the hosts and host plants published for $P$. pectinicornis (Noyes, 2002) indicates a preference for hosts in the lower strata of vegetation, which may explain the absence of this species in our samples from tall trees. P. pectinicornis is sometimes recorded as a major element in the $C$. ohridella parasitoid complex (Horváth \& Benedek, 2001, and references therein). However, these records should be interpreted with care, since $P$. pectinicornis and the closely related $P$. agraules are considered to be conspecific by some European taxonomists. The latter is one of the most important parasitoids of the horse chestnut leafminer in Europe. Both, the absence of records of $S$. sericeicornis in late spring and $P$. pectinicornis from mature trees, would merit further investigation.

The eulophid parasitoids constituting the parasitoid complex of $C$. ohridella are known to exploit a wide range of concealed hosts of many different taxonomic groups (Noyes, 2002). However, the chalcidoid faunas at least of tree leaf-mining Lepidoptera, Coleoptera and Hymenoptera are qualitatively very similar, whereas those of Diptera are rather different (Askew \& Shaw, 1974). The constraints limiting the polyphagy of eulophid parasitoids of leafminers are linked more to the host plant than the host insect (Askew \& Shaw, 1986). The Diptera mentioned in this study are therefore not necessarily the best alternative hosts for the parasitoids of $C$. ohridella, nevertheless they were the only ones present in early spring. In the case of $M$. buxi and $P$. ilicis, the lack of any parasitoids frequently found on $C$. ohridella may also be caused by the toxicity of the host plants, or simply by the hardness of the leaf substrate enclosing the host, which could represent an impenetrable barrier to the parasitoid's ovipositor (Quicke et al., 1999). Askew \& Shaw (1974) indicate that a special parasitoid complex is associated with leafminers of hard, evergreen tissues.

With regard to the constraints mentioned above, the similarity between the parasitoid complexes of the agromyzid species and the horse chestnut leafminer are remarkable. None of the parasitoid species reared from Lonicera in this study were recorded from leafmining flies on this host plant by Askew \& Shaw (1974). Most of the parasitoid complex on honeysuckle probably came from horse chestnut leaf litter, since the sample was collected from around mature horse chestnut. The early emergence of the parasitoids and the lack of alternative hosts may have caused these species to attack the leafmining flies on honeysuckle. Although suboptimal as hosts, agromyzid leafminers may provide an alternative resource capable of sustaining $C$. ohridella parasitoids in early spring and reduce the tendency of certain species to leave the locality after hibernation. In the study by Girardoz et al. (2006), the moth infesting horse chestnut in diverse habitats, with presumably many alternative hosts, were not higher parasitized than those infesting trees growing in less diverse habitats. Unfortunately, as in our own investigation, quantitative data on the alternative hosts were not collected. Further parasitoid web studies are therefore needed to assess the influence of the availability of alternative hosts on the parasitism of $C$. ohridella.

ACKNOWLEDGEMENTS. The majority of the parasitoids found in this study were determined by the senior author, nevertheless we are deeply indebted to $\mathrm{H}$. Baur, Bern $(\mathrm{CH})$, for determination of the pteromalids; to R. Askew, Beeston (UK), for differentiation of the Pnigalio spp.; to C. Hansson, Lund (S) for determination of the Chrysocharis spp.; to A. Taeger, Müncheberg (D) for determination of the braconids and to M. von Tschirnhaus, Bielefeld (D) for help with the leafmining flies. Many thanks go to A. Liston, Müncheberg (D) for proofreading the English. We are also grateful to two anonymous reviewers for their useful comments on an earlier version of the manuscript. The investigations were carried out in the course of the project BerlinCam, funded by the Senate Department of Urban Development, Berlin and the EU through EFRE funds (10700UEP/WÜ5). The public authorities of the district of Neukölln and the managers of Britzer Garten kindly gave us access to the experimental sites.

\section{REFERENCES}

AsKew R.R. \& SHAw M.R. 1974: An account of the Chalcidoidea parasiting leaf mining insects of deciduous trees in Britain. Biol. J. Linn. Soc. 6: 289-335.

AsKew R.R. \& SHAw M.R. 1979: Mortality factors affecting the leaf-mining stages of Phyllonorycter (Lepidoptera: Gracillariidae) on oak and birch. 1. The analysis of the mortality factors. Zool. J. Linn. Soc. 67: 31-49.

Askew R.R. \& Shaw M.R. 1986: Parasitoid communities: Their size, structure and development. In Waage J. \& Greathead D. (eds): Insect Parasitoids. Symp. Royal Entomol. Soc. 13. Academic Press, London, pp. 225-271.

CoRnell H.V. \& Hawkins B.A. 1993: Accumulation of native parasitoid species on introduced herbivores: A comparison of hosts as natives and hosts as invaders. Am. Nat. 141: $847-865$. 
Freise J. \& Heitland W. 2004: Bionomics of the horse-chestnut leaf miner Cameraria ohridella Deschka \& Dimic 1986, a pest on Aesculus hippocastanum in Europe (Insecta, Lepidoptera, Gracillariidae). Sencken. Biol. 84: 61-80.

Girardoz S., Kenis M. \& Quicke D. 2006: Recruitment of native parasitoids by an exotic leafminer, Cameraria ohridella: hostparasitoid synchronization and influence of the environment. Agric. Forest Entomol. 8: 49-56.

Grabenweger G. 2003: Parasitism of different larval stages of Cameraria ohridella. Biocontrol 48: 671-684.

Grabenweger G. 2004: Poor control of the horse chestnut leafminer, Cameraria ohridella (Lepidoptera: Gracillariidae), by native European parasitoids: a synchronisation problem. Eur. J. Entomol. 101: 189-192.

Grabenweger G. \& Lethmayer C. 1999: Occurrence and phenology of parasitic Chalcidoidea on the horse chestnut leafminer Cameraria ohridella Deschka \& Dimic (Gracillariidae, Lepidoptera). J. Appl. Entomol. 123: 257-260.

Grabenweger G., Avtzis N., Girardoz S., Hrasovec B., Tomov R. \& KenIS M. 2005: Parasitism of Cameraria ohridella (Lepidoptera, Gracillariidae) in natural and artificial horse-chestnut stands in the Balkans. Agric. Forest Entomol. 7: 291-296.

Heitland W., Kopelke J.-P. \& Freise J. 2003: Die Roßkastanien-Miniermotte - 19 Jahre Forschung und noch keine Lösung in Sicht? Natur Mus. 133: 221-231.

HellRigl K. 2001: Neue Erkenntnisse und Untersuchungen über die Roßkastanien-Miniermotte Cameraria ohridella Deschka \& Dimic, 1986 (Lepidoptera, Gracillariidae). Gredleriana 1: 9-81.

Hellrigl K. 2003: Cameraria ohridella: a che punto siamo arrivati? Proceedings of the Symposium on Important Horse
Chestnut Pests and Pathogens. University of Bologna, Bologna, pp. 63-68.

Horváth B. \& Benedek P. 2001: Parasitoiden der RoßkastanienMiniermotte (Cameraria ohridella Deschka \& Dimic, 1986) in Nordwest-Ungarn. Acta Agron. Ovar. 43: 35-48.

Jäckel B., Balder H., Grabenweger G., Hopp H., Кoch T. \& SCHMOLling S. 2006: Standortabhängiges Parasitierungsverhalten von Gegenspielern der Roßkastanienminiermotte (Cameraria ohridella) in Berlin. Mitt. Dt. Gesell. Allgem. Angew. Entomol. 15: 81-84.

Mey W. 1991: Über die Bedeutung autochtoner Parasitoidenkomplexe bei der rezenten Arealexpansion von vier Phyllonorycter-Arten in Europa (Insecta, Lepidoptera, Hymenoptera). Mitt. Zool. Mus. Berlin 67: 177-194.

Mey W. 1993: Zur Parasitierung der Pfennigminiermotte, Leucoptera malifoliella (Costa), (Lepidoptera, Lyonetiidae) im Havelländischen Obstbaugebiet. J. Appl. Entomol. 115: 329-341.

Miller P.F. 1973: The biology of some Phyllonorycter species (Lepidoptera: Gracillariidae) mining leaves of oak and beech. J. Nat. Hist. 7: 391-409.

Noyes J. 2002: Interactive catalogue of world Chalcidoidea. CD-ROM, Taxapad, Vancouver.

Quicke D., Leralec A. \& Vilhelmsen L. 1999: Ovipositor structure and function in the parasitic Hymenoptera with an exploration of new hypotheses. Atti Accad. Naz. Ital. Entomol. Rend. 47: 197-239.

ZwÖLFER H. 1962: Die Orientierung entomophager Parasiten als Problem der angewandten Entomologie. J. Appl. Entomol. 50: 93-98.

Received June 12, 2006; revised and accepted September 11, 2006 